\title{
Anatomic variation of the flexor digiti minimi brevis muscle: a morphological and functional study: case report
}

\author{
MORAES, V. V. S., SIQUEIRA, S. L. *, RODRIGUES, F. P., QUEIROZ, E. B. B., \\ PINTO, I. C. T. and TORRES, G. M.
}

\begin{abstract}
Department of Anatomy, Faculdade de Ciências Médicas de Minas Gerais - CMMG, Alameda Ezequiel Dias, 275, CEP 30130-110, Belo Horizonte, MG, Brazil

*E-mail: saviolanasiqueira@gmail.com
\end{abstract}

\begin{abstract}
Introduction: A great amount of accessory and supernumerary muscles, or even their absence, has already been described in medical literature, related to Anatomy, Surgery and Radiology. In the majority of cases, muscles with any morphological changes, in their origins, insertions, number of muscle bellies and anomalous vascular or nervous patterns, are asymptomatic. However, approximately $3 \%$ of compression neuropathy cases are results of an anomalous muscle. Material and methods: During a routine dissection, an anatomical variation was found on the left hypothenar region of an afrodescendant adult's corpse, which led the authors to further investigate its incidence and the clinical significance of this variation, basing up of articles published in refereed journals and renowned books on this subject. Results: Many authors have already identified numerous muscle variations in the hypothenar region, whether in dissection labs or in private clinics. Since some muscular variations may cause numerous clinical symptoms, it's important to have a detailed anatomical knowledge of the correspondent region. There are cases of ulnar nerve compression caused by an anomalous flexor digiti minimi brevis described in the medical literature. The majority of authors explained the nervous and vascular compression from some factors as injury, small repetitive traumas, genetically predetermined muscle size and muscular hypertrophy. Conclusion: The importance of differential diagnosis to any affections of the hypothenar region lies on the anatomical and surgical knowledge of the structures quoted in this study, the statistics related to the prevalence of these anatomical variations and the relevance of these in the present case.
\end{abstract}

Keywords: anatomical variation, hypothenar region, accessory muscles, flexor digiti minimi brevis, anatomy, surgery, radiology.

\section{Introduction}

A great amount of accessory and supernumerary muscles, or even their absence, has already been described in medical literature, related to Anatomy (CLEMENTE, 1985; KING and O'RAHILLY, 1950; MORISSON, 1916; SAADEH and BERGMAN, 1988), Surgery and Radiology. In the majority of cases, muscles with any morphological changes, in their origins, insertions, number of muscle bellies and anomalous vascular or nervous patterns, are asymptomatic. However, approximately $3 \%$ of compression neuropathy cases are results of an anomalous muscle (SHEA and MCCLAIN, 1969). They are commonly found incidentally, during surgeries or imaging exams. Symptoms may be associated to palpable swelling, or as a result of impairment of neurovascular structures (PAPATHANASIOU, LOIZIDES, PANAYIOTOU et al., $2005)$, typically in osteofibrous tunnels. In cases which an obvious cause for these symptoms is absent, the recognizement and careful evaluation of the anatomical variation improves the diagnosis and treatment of the infirmity (SOOKUR, NARAGHI, BLEAKNEY et al., 2008).

\section{Case Report}

During a routine dissection at the Anatomy Lab of the University Faculdade de Ciências Médicas de Minas Gerais, an anatomical variation was found on the left hypothenar region of an afro descendant adult's corpse. The flexor digiti minimi brevis muscle possessed a normal topography, excluding the unusual presence of two bellies, different from each other and well defined, constituting the muscle (Figure 1). The lateral belly presented to be thicker than the medial belly, measuring 85 millimeters of length and 10 millimeters of width, while the medial one had 74 millimeters of length and 9 millimeters of width. Both parts stemmed from the hamulus hamatum and the flexor retinaculum, and inserted medially at the basis of the proximal phalanx of the fifth finger, along with the abductor digiti minimi tendon (Figure 2). Both bellies were innervated by the deep branch of the ulnar nerve, without any other changes in the patterns of neurovascular branching in this region. All of the other hand muscles presented without any anatomical variation. The superficial branch oh the ulnar nerve also presented to be normal, without any sign of presence of a compression neuropathy.

As the normal patterns of innervation and vascularization in the hypothenar region were maintained, difficultly it would be possible to occur any symptomatology related to the anatomical variation described in this case, most probably by hypertrophy or trauma to the muscle quoted here.

In this same institution, of a 107 dissected corpses, only the specimen described in this study presented with such anatomical variation. 


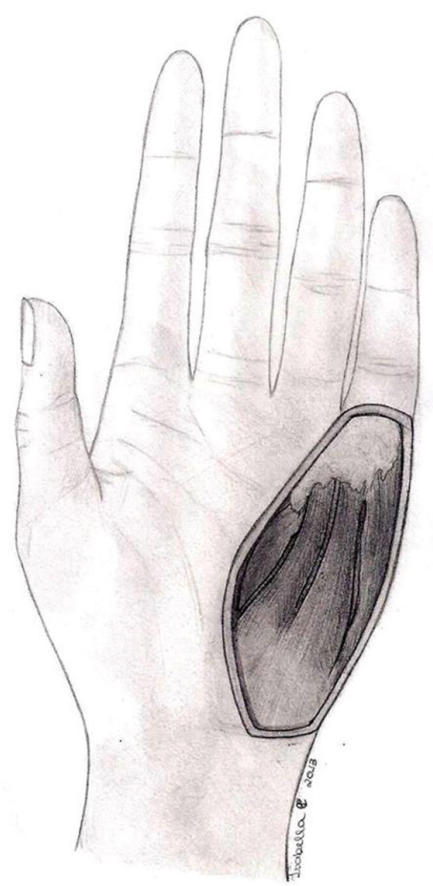

Figure 1. Sketch of the hypothenar region with anatomical variation (flexor digiti minimi brevis composed by two muscle bellies).

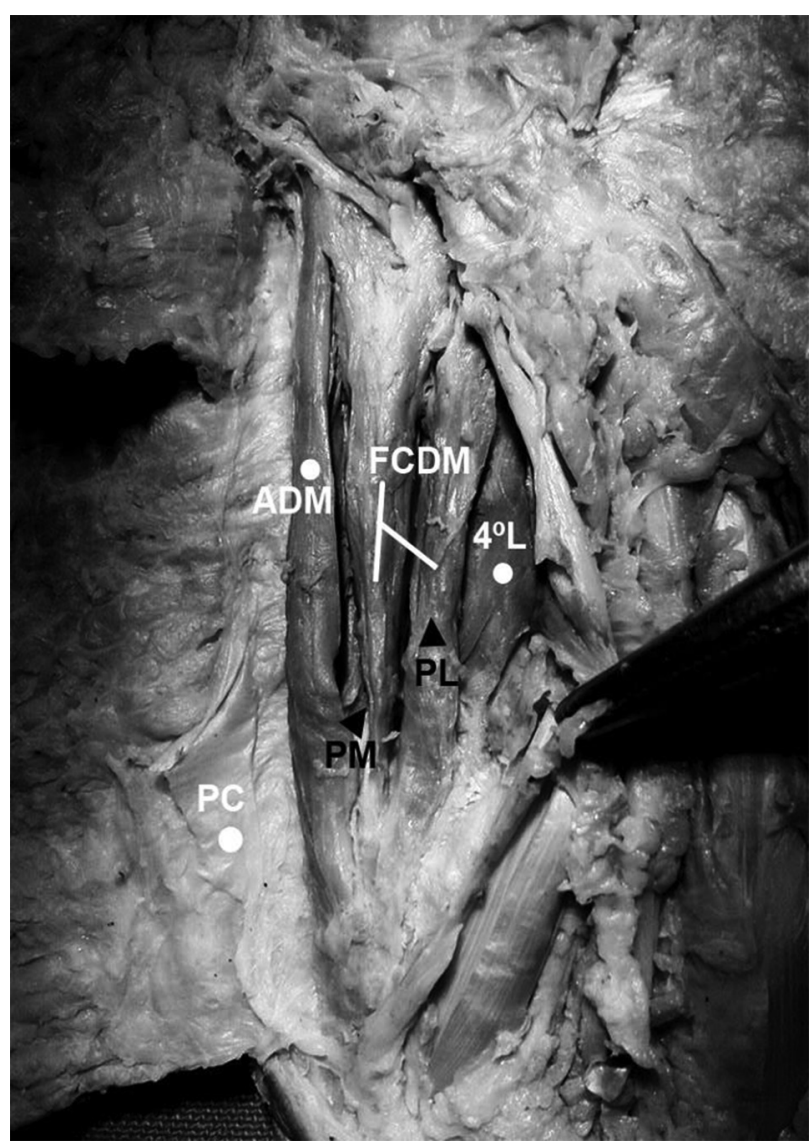

Figure 2. Photo from dissection of our subject of study. ADM (abductor digiti minimi); FCDM (flexor digiti minimi brevis); $4^{\circ} \mathrm{L}$ (fourth lumbrical); PC (palmaris brevis); PM (medial portion of FCDM); PL (lateral portion of FCDM).

\section{Discussion}

Many authors have already identified numerous muscle variations in the hypothenar region, whether in dissection labs or in private clinics (BUCHER, 1943; WAHBA, SINGH and LOZANOFF, 1998; WINGERTER, GUPTA, LE et al., 2003). The muscle of the hypothenar region most often quoted in anatomical variation descriptions is the abductor digiti minimi, with a prevalence of $24 \%$, possessing quite variable origins (SOOKUR, NARAGHI, BLEAKNEY et al., 2008). Harvie, Patel and Ostlere (2004), held ultrasonography examinations in 116 wrists of asymptomatic volunteers, and identified the presence of an anomalous muscle in $35 \%$ of the cases, while $50 \%$ of these same cases where bilateral.

Macalister (1875) has already described numerous anatomical variations of the flexor digiti minimi brevis, such as its absence, or evidence of the presence of a palmar accessory belly, the presence of a belly inserting in the metacarpal bone, and its fusion with the abductor digiti minimi muscle. Other authors described its origin from the antebrachial fascia, fusion with the opponens digiti minimi muscle, and the substitution of the flexor digiti minimi brevis by a tendinous sheath, originating from the flexor carpi ulnaris muscle, and inserting in the fifth proximal phalanx and in the hamate bone, just like the presence of an accessory flexor digiti minimi brevis muscle (GEORGIEV and JELEV, 2011; GEORGIEV, JELEV and KINOV, 2010; MADHAVI and HOLLA, 2003).

It's important to describe the intimate relation of the muscles of the hypothenar region whit the adjacent neurovascular structures: the ulnar nerve divides itself in superficial and deep terminal branches. The superficial branch crosses the superficial palmar arch by its medial side and lies on the hypothenar muscles, of which the majority is innervated by the deep terminal branches (BAKINDE, YOTOVSKI, VOIGT et al., 2005). The deep branch passes deeply between the abductor digiti minimi and the flexor digiti minimi brevis muscle, which it innervates. It passes through a fibrous arch in the proximal extremity of the opponens digiti minimi and innervates this muscle. After, this branch surrounds the hamulus hamatum and expands laterally with the deep palmar arch under the protection of a fat pad located underneath the flexor tendons. In this part of its route, the deep branch innervates all the interosseous muscles, the third and fourth lumbricals, the aductor pollicis muscle and, usually, the flexor digiti minimi brevis, in which it penetrates (GARDNER, GRAY and O'RAHILLY, 1967). Since some muscular variations may cause numerous clinical symptoms, it's important to have a detailed anatomical knowledge of the correspondent region.

There are cases of ulnar nerve compression caused by an anomalous flexor digiti minimi brevis described in the medical literature (SÄLGEBACK, 1977; SPINNER, LINS and SPINNER, 1978; GEORGIEV, JELEV and SURCHEV, 2007). In addition to the compression of neural structures, a muscle with any anatomical variation may be associated to ulnar artery thrombosis in the Guyon's canal (PRIBYL and MONEIM, 1994). The majority of authors explained the nervous and vascular compression from some factors as injury, small repetitive traumas, genetically predetermined muscle size and muscular hypertrophy (CURRY and KUZ, 2000). Other predisponent factors are the presence of dilated and sinuous vases (JOSE, BRAGG and SRIVASTAVA, 2006) ganglion cysts, schwanomas, abnormally long carpal bones, edema and 
fibrous tissue masses inside the distal ulnar tunnel (MURATA, SHIH and TSAI, 2003). In these cases, ultrasonography and magnetic resonance exams could be useful in the diagnosis of the muscle that has the anatomical variation (ZEISS, JAKAB, KHIMJI et al., 1992; ZEISS and GUILLIAM-HAIDET, 1996; TIMINS, 1999).

\section{Conclusion}

A big number of anatomical variations similar to the described in this study have already been published in surgical and radiological literature, mostly in case reports. The big majority of anatomical variations in muscles is asymptomatic, and tends to represent accidental discoveries in surgeries and imaging exams. Symptomatic cases may be related to palpable swelling, or even compression neuropathies, especially in Guyon's canal.

The importance of differential diagnosis to any affections of the hypothenar region lies on the anatomical and surgical knowledge of the structures quoted in this study, the statistics related to the prevalence of these anatomical variations and the relevance of these in the present case.

The detailed anatomy of this study may improve the surgeon's knowledge and experience in the diagnosis and treatment of the pathologies that may affect the hypothenar region, including trauma, Guyon's canal compression and benign and malign tumors of this region.

\section{References}

BAKINDE, N., YOTOVSKI, P., VOIGT, T. and RAGER, G. Accessory muscle in the hypothenar region: a functional approach. Annals of Anatomy, 2005, vol. 187, n. 2, p. 149-152. PMid:15900700.

BUCHER, O. Uber die Varietäten des $\mathrm{M}$ abductor digiti quinti. Annals of Anatomy, 1943, vol. 94, p. 317-324.

CLEMENTE, CD. Anatomy of the human body. Philadelphia: Lea \& Febiger, 1985. p. 553-554.

CURRY, B. and KUZ, J. A new variation of abductor digiti minimi accessorius. The Journal of Hand Surgery, 2000, vol. 25, n. 3, p. 585587. http://dx.doi.org/10.1053/jhsu.2000.6004. PMid:10811767.

GARDNER, E., GRAY, D.J. and O'RAHILLY, R. A mão. In GARDNER, E., GRAY, D.J. and O'RAHILLY, R. Anatomia: estudo regional do corpo humano. 2nd ed. Rio de Janeiro: Guanabara Koogan, 1967. p. 163-180. chap. 17.

GEORGIEV, G. and JELEV, L. An aberrant flexor digiti minimi brevis manus muscle. The Journal of Hand Surgery, 2011, vol. 36, n. 12, p. 1965-1967. http://dx.doi.org/10.1016/j.jhsa.2011.09.002. PMid:22014444.

GEORGIEV, G., JELEV, P. and SURCHEV, L. Undescribed variant muscle: "Deep abductor-flexor" of the little finger, in relation to ulnar nerve compression at the wrist. Anatomische Gesellschaft, 2007, vol. 189, n. 3, p. 276-282. PMid:17534035.

GEORGIEV, G.P., JELEV, L. and KINOV, P. Aberrant muscles at the Guyon's canal. International Journal Of Anatomical Variations, 2010, vol. 3, n. 1, p. 67-69.

HARVIE, P., PATEL, N. and OSTLERE, SJ. Prevalence and epidemiological variation of anomalous muscles at Guyon's canal. The Journal of Hand Surgery, 2004, vol. 29, n. 1, p. 26-29. http:// dx.doi.org/10.1016/j.jhsb.2003.08.004. PMid:14734065.
JOSE, R., BRAGG, T. and SRIVASTAVA, S. Ulnar nerve compression in guyon's canal in the presence of a tortuous ulnar artery. The Journal of Hand Surgery, 2006, vol. 31, n. 2, p. 200-202. http://dx.doi. org/10.1016/j.jhsb.2005.10.003. PMid:16290914.

KING, S. and O'RAHILLY, R. Palmaris accessorius and duplication of m. palmaris longus. Acta Anatomica, 1950, vol. 10, n. 3, p. 327 331. http://dx.doi.org/10.1159/000140477. PMid:14777258.

MACALISTER, A. Observations on the muscular anomalies in the human anatomy: third series with a catalogue of the principal muscular variations hitherto published. Transactions Of The Royal Irish Academy, 1875, vol. 25, n. 1, p. 1-130.

MADHAVI, C. and HOLLA, SJ. Anomalous flexor digiti minimi brevis in Guyon's canal. Clinical Anatomy, 2003, vol. 16, n. 4, p. 340-343. http://dx.doi.org/10.1002/ca.10087. PMid:12794919.

MORISSON, JT. A palmaris longus muscle with a reversed belly, forming an accessory flexor muscle of the little finger. Journal of Anatomy and Physiology, 1916, vol. 50, n. Pt 4, p. 324-326. PMid:17233073.

MURATA, K., SHIH, J. and TSAI, T. Causes of ulnar tunnel syndrome: a retrospective study of 31 subjects. The Journal of Hand Surgery, 2003, vol. 28, n. 4, p. 647-651. http://dx.doi.org/10.1016/S03635023(03)00147-3. PMid:12877855.

PAPATHANASIOU, E.S., LOIZIDES, A., PANAYIOTOU, P., PAPACOSTAS, S.S. and KLEOPA, KA. Ulnar neuropathy at Guyon's canal: electrophysiological and surgical findings. Electromyograoby And Clinical Neurophisiology, 2005, vol. 45, n. 2, p. 87-92. PMid:15861858.

PRIBYL, C.R. and MONEIM, MS. Anomalous hand muscle found in the Guyon's canal at exploration for ulnar artery thrombosis: a case report. Clinical Orthopaedics And Related Search, 1994, vol. 306, n. 306, p. 120-123. PMid:8070182.

SAADEH, F.A. and BERGMAN, RA. An unusual accessory flexor (opponens) digiti minimi muscle. Annals of Anatomy, 1988, vol. 165, n. 4, p. 327-329. PMid:3400896.

SÄLGEBACK, S. Ulnar tunnel syndrome caused by anomalous muscles: case report. Scandinavian Journal of Plastic and Reconstructive Surgery, 1977, vol. 11, n. 3, p. 255-258. http://dx.doi. org/10.3109/02844317709025529. PMid:609911.

SHEA, J.D. and MCCLAIN, EJ. Ulnar-nerve compression syndromes at and below the wrist. The Journal Of Bone and Joint Surgery, 1969, vol. 51, n. 6, p. 1095-1103. PMid:5805411.

SOOKUR, P.A., NARAGHI, A.M., BLEAKNEY, R.R., JALAN, R., CHAN, O. and WHITE, LM. Accessory muscles: anatomy, symptoms, and radiologic evaluation. Radiographics, Oak Brook, 2008, vol. 28, n. 2, p. 481-499. http://dx.doi.org/10.1148/rg.282075064. PMid:18349452.

SPINNER, R.J., LINS, R.E. and SPINNER, M. Compression of the medial half of the deep branch of the ulnar nerve by an anomalous origin of the flexor digiti minimi: a case report. The Journal Of Bone \& Joint Surgery, 1978, vol. 3, n. 78, p. 427-430.

TIMINS, ME. Muscular anatomic variants of the wrist and hand: findings on MR imaging. AJR. American Journal of Roentgenology, 1999, vol. 172, n. 5, p. 1397-1401. http://dx.doi.org/10.2214/ ajr.172.5.10227524. PMid:10227524.

WAHBA, M.Y., SINGH, G.D. and LOZANOFF, S. An anomalous accessory flexor digiti minimi profundus muscle: a case study. Clinical Anatomy, 1998, vol. 11, n. 1, p. 55-59. http://dx.doi.org/10.1002/ (SICI)1098-2353(1998)11:1<55::AID-CA9>3.0.CO;2-R. PMid:9445099.

WINGERTER, S., GUPTA, S., LE, S., SHAMASUNDER, S., BERNSTEIN, R., RABITAILLE, W., KUKUYEVA, Y. and DOWNIE, 
MORAES, V. V. S., SIQUEIRA, S. L., RODRIGUES, F. P. et al.

S. Unusual origin of the flexor digiti minimi brevis muscle. Clinical Anatomy, 2003, vol. 16, n. 6, p. 531-533. http://dx.doi.org/10.1002/ ca.10122. PMid:14566903.

ZEISS, J. and GUILLIAM-HAIDET, L. MR Demonstration of anomalous muscles about the volar aspect of the wrist and forearm. Clinical Imaging, 1996, vol. 20, n. 3, p. 219-221. http://dx.doi. org/10.1016/0899-7071(95)00013-5. PMid:8877177.
ZEISS, J., JAKAB, E., KHIMJI, T. and IMBRIGLIA, J. The ulnar tunnel at the wrist (Guyon's canal): normal MR anatomy and variants. American Journal of Roentgenology, 1992, vol. 158, n. 5, p. 1081-1085. http://dx.doi.org/10.2214/ajr.158.5.1566671. PMid:1566671.

Received July 10, 2014 Accepted February 25, 2016 